Int. J. Dev. Biol. 55: 933-943

doi: $10.1387 / \mathrm{ijdb} .113326 \mathrm{ao}$

\title{
Tgm2/Gh, Gbx1 and TGF- $\beta$ are involved in retinoic acid-induced transdifferentiation from epidermis to mucosal epithelium
}

\author{
AKIKO OBINATA ${ }^{\dagger, 1}$, KEITAROU OSAKABE ${ }^{1}$, MARI YAMAGUCHI $^{1}$, \\ RIYO MORIMOTO ${ }^{1}$ and YOSHIHIRO AKIMOTO*,2 \\ ${ }^{1}$ Department of Physiological Chemistry II, Faculty of Pharmaceutical Sciences, Teikyo University, Japan and \\ ${ }^{2}$ Department of Anatomy, Kyorin University School of Medicine, Mitaka, Tokyo, Japan
}

\begin{abstract}
We previously demonstrated that retinoic acid (RA) induces epidermis to transdifferentiate to mucosal epithelium with goblet cells in chick embryonic cultured skin. To characterize the molecular mechanism of this transdifferentiation process, we used rat embryonic cultured skin and immunohistochemistry to confirm that RA-induced epidermal transdifferentiation accompanies the expression of markers of esophagus epithelium. Because Gbx1, TG2/Gh (transglutaminase2) and TGF- $\beta 2$ are reported individually to be induced by RA in cultures of chick embryonic skin, mouse epidermal cells and human hair follicles respectively, here, we investigated whether cooperative interplay of Gbx1, TG2/Gh and TGF- $\beta 2$ is required for the transdifferentiation of epidermal cells to mucosal cells. We have shown that expression of Gbx1, TG2/Gh and TGF- $\beta$ proteins were all upregulated in RA-induced transdifferentiated skin and that the former two were expressed in the epidermis, whileTGF- $\beta$ was expressed in the dermis. Inhibitors of theTGF- $\beta$ signal pathway partially inhibited transdifferentiation. Overexpression of both $h T G 2 / G h$ and $m G b x 1$ together in the epidermis by electroporation resulted in cuboidal cells in the upper cell layers of the epidermis without keratinized layers, although epidermal keratinization was observed in skin by overexpression of either of them. Labeling DNA with BrdU indicated that RA directly transdifferentiated transient amplifying epidermal cells, not stem cells, to mucosal cells. This study showed that coexpression of $T G / 2$ and $G b x 1$ in the epidermis was required for esophagus-like mucosal transdifferentiation, and that increase in TGF- $\beta 2$ expression by RA in the dermis was essential to induce transdifferentiation through epithelial-mesenchymal interaction.
\end{abstract}

KEY WORDS: retinoic acid, skin, transdifferentiation, mucosal epithelium, epithelial-mesenchymal interaction

\section{Introduction}

Epithelial-mesenchymal interactions are important in development, cellular growth and differentiation both during embryogenesis and in adult animals, including reproduction (Sengel 1976). Retinoids function as important regulatory signaling molecules in these processes. Using chick embryonic cultured skin, we showed previously that RA induced transdifferentiation of the epidermis to mucosal epithelium containing Goblet cells by combined culture of undifferentiated epidermis with retinol or RA-pretreated dermis (Obinata et al., 1987). This transdifferentiation accompanied increase in mRNA expression of Gbx1, a divergent type of the homeobox transcription factor, in the epidermis through epithelialmesenchymal interaction (Obinata et al., 2001), and the signals induced in the dermis during the first $8 \mathrm{~h}$ of culture by retinol required new protein synthesis (Obinata et al., 1991a). To know the molecular mechanism of the transdifferentiation induced by RA, we established a culture system where RA induced epidermal transdifferentiation accompanying the expression of markers of esophagus epithelium using rat embryonic skin, as it is easier than chick embryonic skin in immunohistochemical analysis. Then, we studied about cooperative interplay of Gbx1, TG2/Gh and TGF- $\beta 2$ as they are reported to be induced individually by RA in cultures of chick embryonic skin (Obinata et al., 2001), mouse epidermal

Abbreviations used in this paper: BPNH2, biotinylated pentylamine; Gbx 1, gastrulation brain homeobox 1; HE, hematoxylin and eosin; PAS, periodic acid-Schiff; RA, retinoic acid; TG, transglutaminase; TGF, transforming growth factor.

\footnotetext{
*Address correspondence to:YoshihiroAkimoto. Department of Anatomy, Kyorin University School of Medicine, Mitaka, Tokyo 181-8611, Japan.

Tel:+81-422-47-5511. Fax:+81-422-44-0866. e-mail: yakimoto@ks.kyorin-u.ac.jp
} 
cells (Lichti and Yuspa 1985a) and human hair follicles (Foitzik et al., 2005) respectively. Studies of Gbx1 have concentrated on the brain or neurons (Rhinn et al., 2004; Asbreuk et al., 2002)
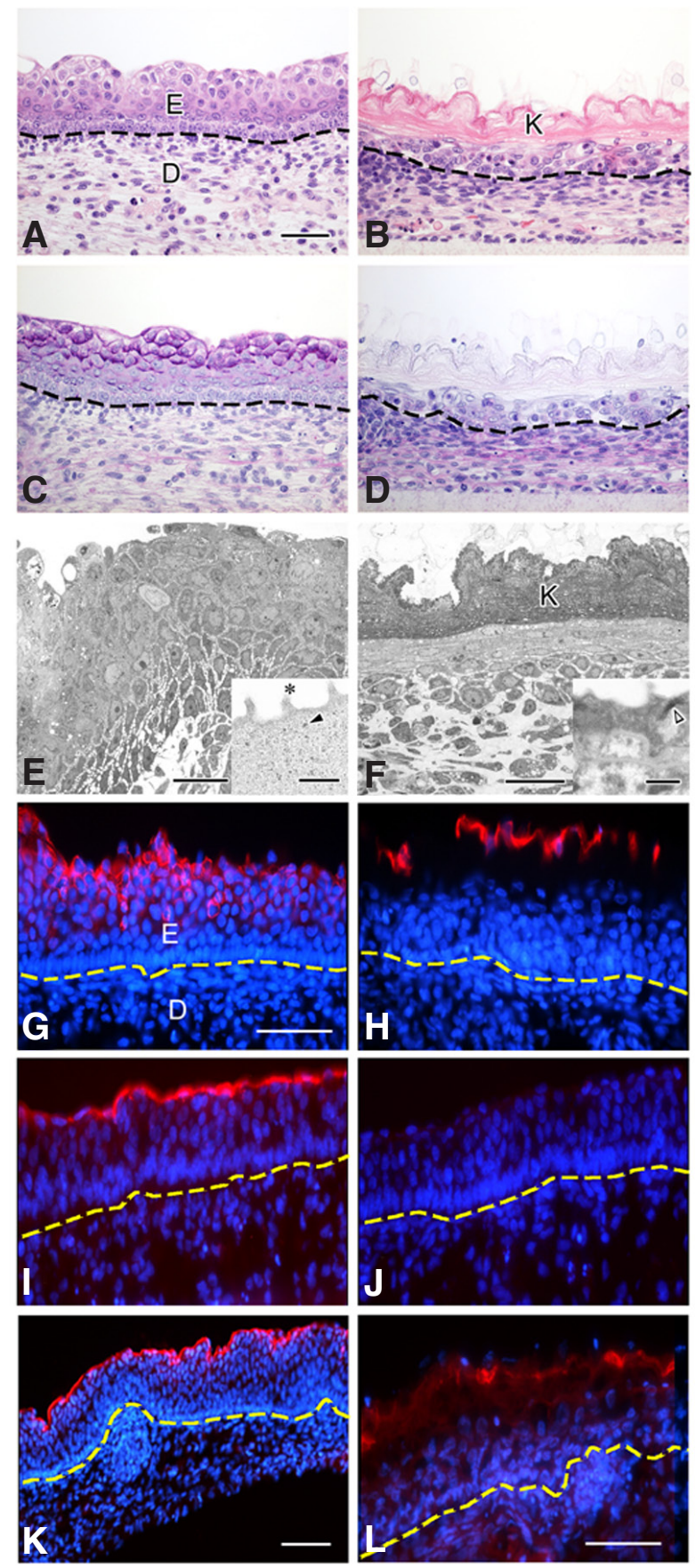

and are poor in other tissues. RA induces a catagen-like stage in human hair follicles, accompanying upregulation of TGF- $\beta 2$ in the dermal papilla, resulting in hair loss (Foitzik et al., 2005). Retinoic acid is a consistent inducer of TG2/Gh expression in various cells and tissues (Singh et al., 2003; Ou et al., 2000; Antonyak et al., 2001). In mammalian epidermal cells, $3 \mu \mathrm{M}$ retinoic acid induces tissue transglutaminase (TG2/Gh) (Lichti et al., 1985b). TG2/Gh knockout mice do not have any defects in the keratinocytes differentiation program (Nanda et al., 2001). TG2/Gh is the most diverse and ubiquitous enzyme of the transglutaminase family (Lorand and Graham, 2003) and is implicated in diverse processes such as inflammation, wound healing, apoptosis, neurodegenerative disorders and cancer (Fesus and Piacentini 2002; Dalby et al., 2010; Telci and Griffin 2006). The most characteristic enzyme function of the transglutaminase family is calcium-dependent transamidation activity; the formation of $\varepsilon$-( $\gamma$-glutamyl)lysine cross-links between proteins, resulting in polymerization. TG1, TG3 and TG5, the transglutaminase family, are found in mammalian keratinocytes and play an important role in the formation of the stratum corneum in the skin by the introduction of cross-links into proteins (Steinert et al., 1996; Zhang et al., 2005; Candi et al., 2002). In addition to transamidation activity, TG2/Gh functions as a signal-transducing GTP-binding protein (Nakaoka et al., 1994) from classical Gcoupled receptors, serine/threonine kinase (Mishra and Murphy 2004), and a protein-disulfide isomerase that regulates adenylate cyclase (Tucholski and Johnson 2003). This study showed that coexpression of $T G / 2$ and $G b x 1$ in the epidermis was required for esophagus-like mucosal transdifferentiation, and that increase in TGF- $\beta$ expression by RA in the dermis was essential to induce transdifferentiation through epithelial-mesenchymal interaction.

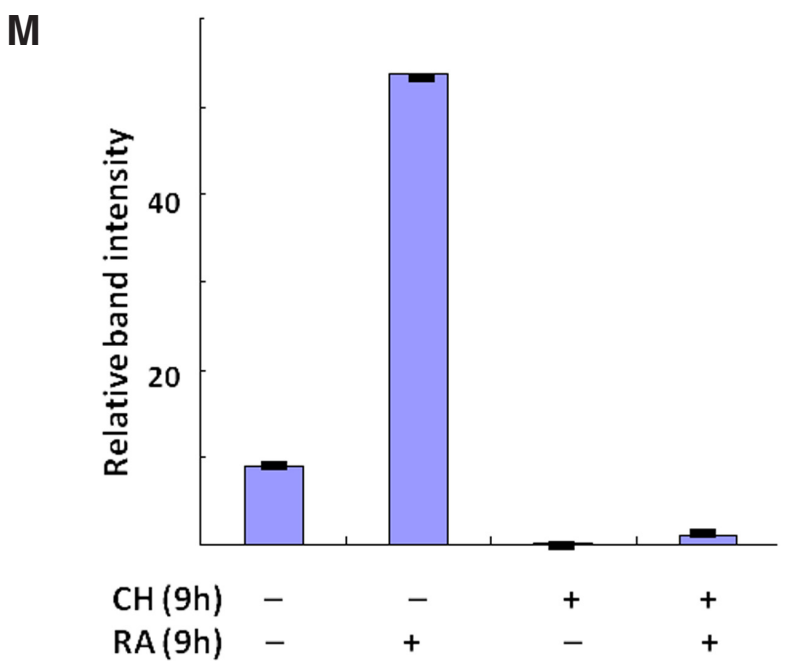

Fig. 1. Transdifferentiation of epidermis of retinoic acid (RA)-pretreated skin to esophagus-like mucosal epithelium. 16E rat embryonic skin was

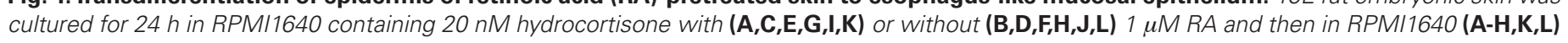
for 4 days. (A,B) Hematoxylin and eosin-stained section. The superficial layers of the epidermis keratinized. (C,D) Periodic acid-Schiff-stained (PAS) section. (E,F) Electron micrograph. Glycogen granules ( ) deposited and microvilli (*) developed in the upper layers of the epidermis, and keratin filaments were not observed throughout the epidermis in RA-pretreated skin (inset of E). Many keratin filaments ( $\square$ ) deposited throughout the epidermis especially in the upper keratinized layers without glycogen granule in control skin (inset of F). (G,H) Immunostaining with anti-K4. (I-L) Immunostaining with anti-MUC4. (G-L) DAPI nuclear counterstain. Dotted lines show boundary between epidermis and dermis. (M) The amount of MUC4 transcript was determined by quantitative RT-PCR analysis. These results were normalized by $\beta$-actin and were compared with those of cultured skin with or without $R A$ and/or cycloheximide (CH) for 9 h. The results are shown as means \pm s.d., $n=3$. K, keratinized layer; $E$, epidermis; $D$, dermis. Scale bars: (A) $100 \mu \mathrm{m}$; (E,F) $50 \mu \mathrm{m}$; insets $500 \mathrm{~nm}$; (G,K,L) $100 \mu \mathrm{m}$. 


\section{Results}

\section{RA induced transdifferentiation of epidermis to mucosal epi- thelium with esophagus markers}

HE and PAS staining histologically showed that the epidermis of RA-pretreated skin transdifferentiated to mucosal epithelium after culture for 4 days (Fig. $1 \mathrm{~A}, \mathrm{C}$ ), while that of control skin keratinized (Fig.1 B,D). Cytokeratin, an intermediate filament, observed mainly in epithelial cells, is an essential cytoskeleton component involved in fixation of the nucleus and maintenance
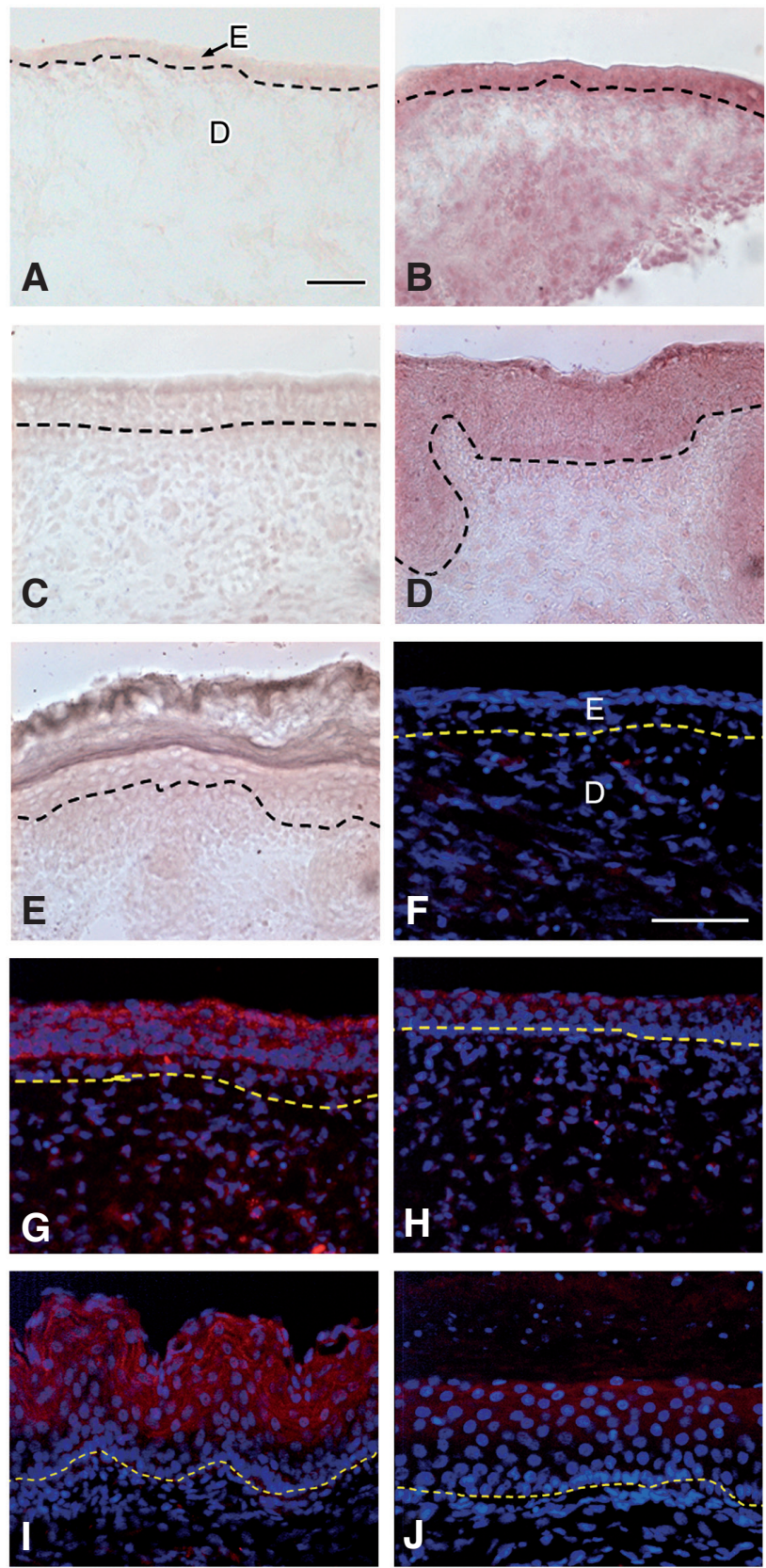

of cell morphology. The cytoskeleton of epithelia is formed by 20 subtypes of cytokeratins whose expression depends primarily on epithelial cell type and degree of differentiation (Bragulla and Homberger 2009). Electron microscopic studies showed that glycogen granules deposited and microvilli developed in the upper layers of the epidermis (Fig. 1E inset), and that keratin filaments were not observed throughout the epidermis in RA-pretreated skin (Fig. 1E), while many keratin filaments (tonofibrils, K1 and K10) deposited at desmosomal junctions in the suprabasal layer of the epidermis without glycogen granule in control skin (Fig. $1 \mathrm{~F}$ and inset). In skin epidermis, basal-specific K5-K14 are expressed in basal proliferative cell layer and other kinds of keratin filaments, K1 and K10, are expressed in the suprabasal layer of the epidermis (Bragulla and Homberger 2009) as was shown in Fig. 6K. As RA-pretreated skin was non-keratinized stratified epithelium, we thought that the epidermis was transdifferentiated to esophagus mucous epithelium. Indeed, in esophagus mucous epithelium, K4 is expressed specifically in upper layers of non-keratinized stratified squamous epithelium starting from the third to fourth layer of epithelial cells, and reaching into the superficial cell layers, but is never found in the cytoplasm of basal cell layer (Fig.1G), where basal-specific keratins K5-K14 are expressed (Bragulla and Homberger 2009).

Indeed, immunostaining with $\mathrm{K} 4$ and MUC4, which are expressed in squamous non-keratinized epithelium and in respiratory and digestive epithelium respectively (Ness et al., 1998; Guillem et al., 2000), showed that the epidermis of RA-pretreated skin expressed both K4 (Fig. 1G) and MUC4 (Fig. 1K) after culture for 4 days, while that of control skin expressed them little, if at all, in peridermal cells (Fig. $1 \mathrm{H}, \mathrm{L}$ ). While $\mathrm{K} 4$ was not expressed after culture for 1 day by RA (data not shown), MUC4 expression was observed after culture for 1 day in the presence of RA (Fig. 1I) but not in the absence of RA (Fig. 1J). Real time PCR analysis indicated that MUC4 expression was increased after $9 \mathrm{~h}$ of RA treatment but was inhibited in the presence of cycloheximide, an inhibitor of protein synthesis (Fig. 1M), indicating that RA did not induce synthesis of MUC4 mRNA directly. Hence, we demonstrated that RA started to induce transdifferentiation of the epidermis to the esophaguslike mucous epithelium as early as $9 \mathrm{~h}$ after RA treatment. The thickness of the epidermis after culture for 5 days was more than 4 times than that of starting epidermis (Fig. 5 E,H,I, Fig. 8 A,B,C) and almost all the basal and suprabasal transient amplifying cells

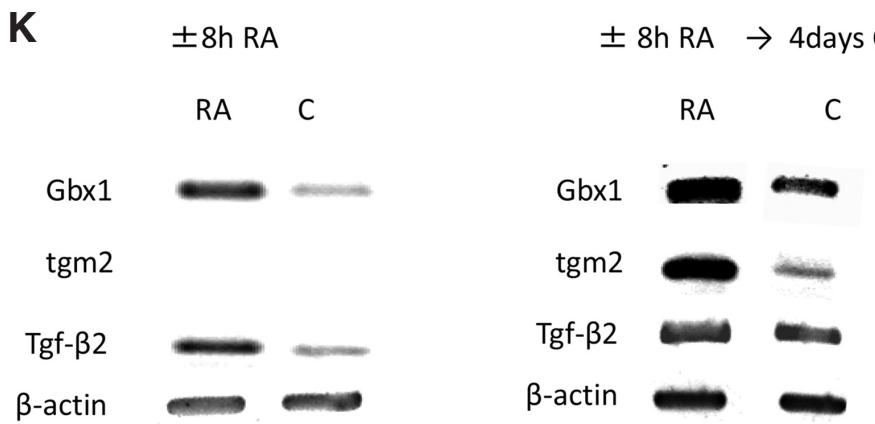

Fig. 2. Increase in expression of mRNA and protein of TG2/Gh in the epidermis by retinoic acid (RA). 16E rat embryonic skin (A,F) was cultured for $24 \mathrm{~h}$ in RPMI1640 containing 20 nM hydrocortisone with (B,D,G,I) or without (C,E,H,J) $1 \mu$ M RA and then in RPMI1640 for 4 days (D,E,I,J). (A-E) In situ hybridization analysis of TG2/Gh mRNA. (F-J) Immunostaining with anti-TG2/Gh. DAPI nuclear counterstain. Dotted lines show boundary between epidermis (E) and dermis (D). Scale bars, $100 \mu \mathrm{m}$. (K) RNA extracted from skin cultured for $8 \mathrm{~h}$ in the presence or absence of RA (left) followed to culture for 4 days without RA (right) was analyzed by RT-PCR at exponentially increasing cycles. 

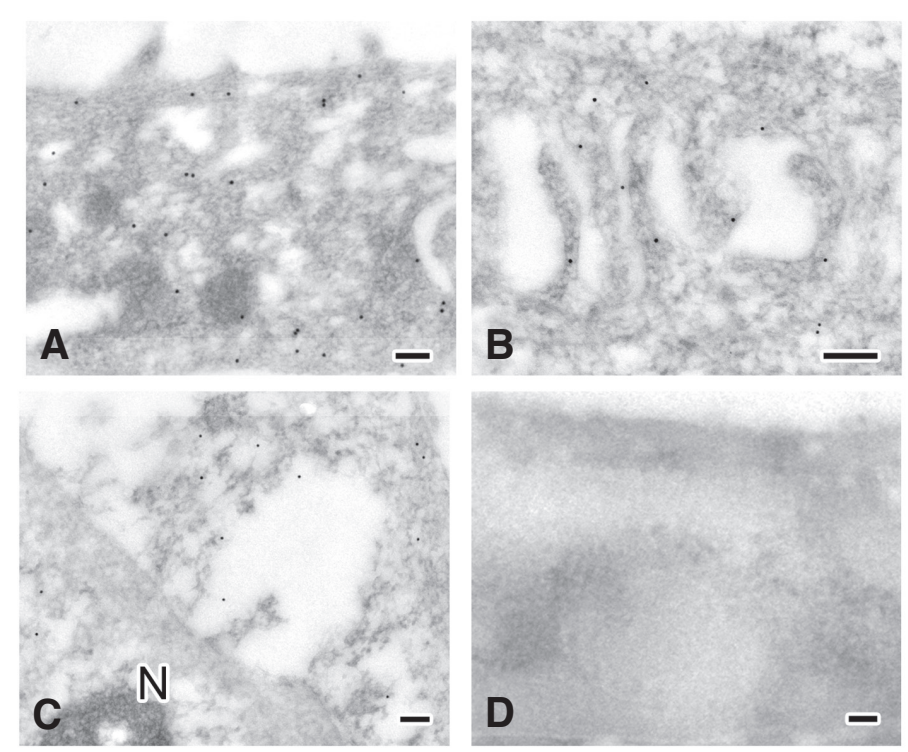

Fig. 3 (Left). Increase in expression of TG2/Gh protein in cytoplasm, the area of cell adhesion and nuclei in epidermis by retinoic acid (RA). Immunoelectron micrograph of anti-TG2/Gh protein reaction as revealed by the colloidal gold labeling technique. 16E rat embryonic skin was cultured for $24 \mathrm{~h}$ in RPMI containing 20 nM hydrocortisone with (A-C) or without (D)
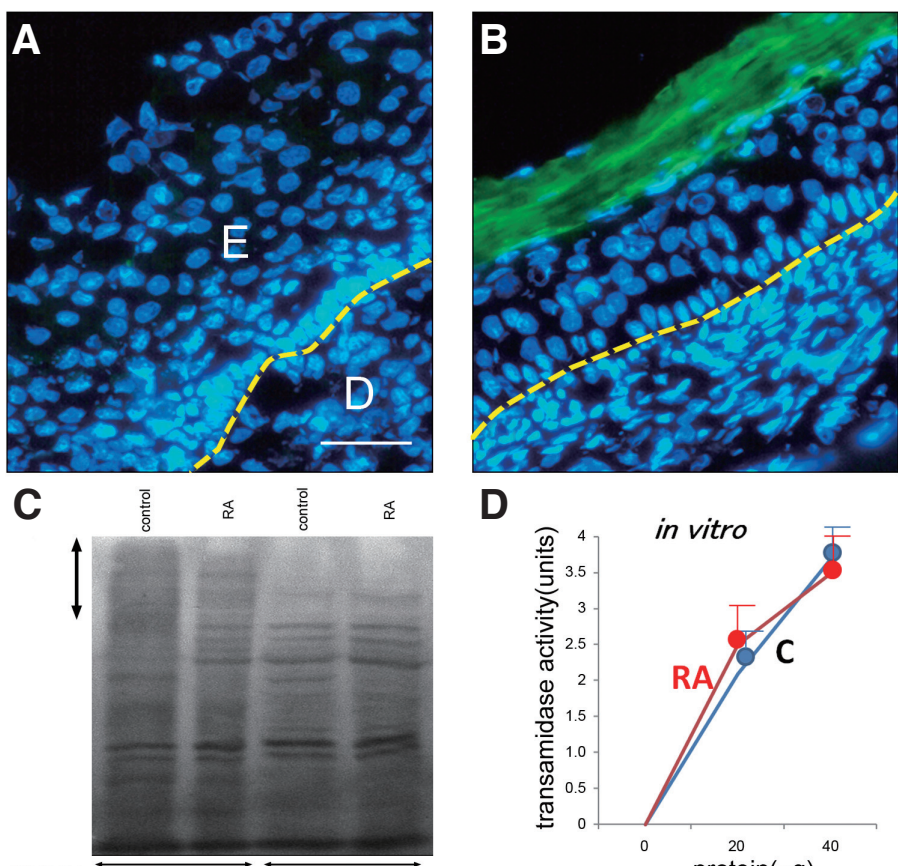

D

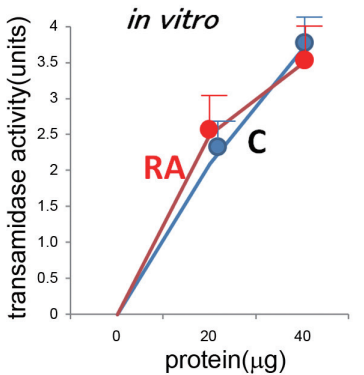

Fig. 4 (Right). Decrease in transamidase activity by retinoic acid (RA). Identification and fractionation of acyl-acceptor transamidase protein substrates in the skin. 16E rat embryonic skin was cultured for $24 \mathrm{~h}$ in RPMI1640 containing 20 nM hydrocortisone with (A) or without (B) $1 \mu M$ RA and then in RPMI1640 for 4 days (A,B). For transglutaminase substrates, 2 mM EZ-Link 5-(biotinamido)pentylamine was added to the culture medium during the last $2 \mathrm{~h}$ of culture. Transamidase activity in RA-pretreated skin (A) decreased compared with that in control skin (B). Dotted lines show boundary between epidermis (E) and dermis (D). (C) Biotinylated substrates in the skin (30 $\mu \mathrm{g}$ protein/well) were separated through standard SDS electrophoresis, and then were transferred to nitrocellulose membrane. The membrane was probed using streptavidin-conjugated horseradish peroxidase ECL Western blotting detection reagents and analysis system. The amount of transamidase substrates in RA-pretreated skin decreased compared with that of control skin $(\leftrightarrow)$ after culture for 4 days. In vitro transamidase activities were the same between RA-pretreated and control skin (D). Bar, $100 \mu$ m.

were extruded from the basal layer and moved to intermediate and finally upper layers of epidermis during culture (Fig. 8 A-C).

Hence, it was confirmed that epidermal stem cells and basal layers are intact.

\section{RA increased expression of $\mathrm{mRNA}$ and protein of TG2/Gh}

Expression of TG2/Gh mRNA increased in the epidermis of the skin cultured for 1 day in the presence of RA (Fig. 2B) and cultured for an additional 4 days without RA (Fig. 2D) when compared with skin without culture (Fig. 2A). Increase in expression of TG2/Gh mRNA was also proved by RT-PCR analysis, while it was not observed after $8 \mathrm{~h}$ of RA treatment (Fig. 2K). The expression was not seen in the absence of RA (Fig. 2 C,E). Expression of TG2/Gh protein increased in the epidermis of the skin cultured for 1 day in the presence of RA (Fig. 2G) and in that of the skin cultured for additional 4 days without RA (Fig. 2l), when compared with the epidermis without culture (Fig. 2F). Strong expression of TG2/Gh protein was observed in the cytoplasm and nuclei of the intermediate and superficial epidermis of RA-pretreated skin (Fig. 2I). The expression was seen a little in the absence of RA (Fig. 2 $\mathrm{H}, \mathrm{J})$. Immunoelectron microscopic study showed that localization of TG2/Gh in the epidermis was shown in cytoplasm after culture for 1 day with RA (data not shown) and in cytoplasm (Fig. 3A), the area of cell adhesion (Fig. 3B) and nuclei (Fig. 3C) throughout the epidermis of RA-pretreated skin after culture for 4 days. No expression was seen in control skin (Fig. 3D) or in the dermis of RA-pretreated skin (data not shown). So, as was expected from multifunctional protein of TG2/Gh (Fesus and Piacentini 2002), it was localized in the various sites in the epidermal cell (Fesus and Piacentini 2002).

\section{In situ and in vitro transamidation activity of TG in RA-pretreated cultured skin}

Biotinylated pentylamine $\left(\mathrm{BPNH}_{2}\right)$, which acts as an acyl-acceptor (Slaughter et al., 1992), enters living cells and acts as a tag that is cross-linked by TG to glutamine donor substrates. When RApretreated skin or control skin was cultured for 4 days and $2 \mathrm{mM}$ $\mathrm{BPNH}_{2}$ was added during the last $1 \mathrm{~h}$ of the culture, incorporation of $\mathrm{BPNH}_{2}$ into the protein of cornified layers of control epidermis was observed, while slight incorporation into the epidermis of RA-pretreated skin was observed (Fig.4 A,B). TG substrates in the dermis were few both in RA-treated skin and control skin (Fig. 4 A,B). When the protein was separated by SDS-PAGE and the blots were probed with streptavidin-peroxidase, specific incorporation of $\mathrm{BPNH}_{2}$ into numerous endogenous protein substrates of TG of high molecular weight was observed in control skin when compared with control skin without $\mathrm{BPNH}_{2}$ (Fig. 4C). On the other hand, TG substrates of high molecular weight decreased in RA- 
pretreated skin (Fig. 4C); however, when transamidase activity, which is regulated by $\mathrm{Ca}^{++}$, was measured in vitro in the presence of a high concentration of $\mathrm{Ca}^{++}$, the activity was the same as that of control skin (Fig. 4D). These results together indicated that, although TG2/Gh of RA-pretreated skin could act as transamidase in vitro, in intact skin, it revealed another enzyme activity of its own at a physiological concentration of $\mathrm{Ca}^{++}$. Indeed, it is reported that
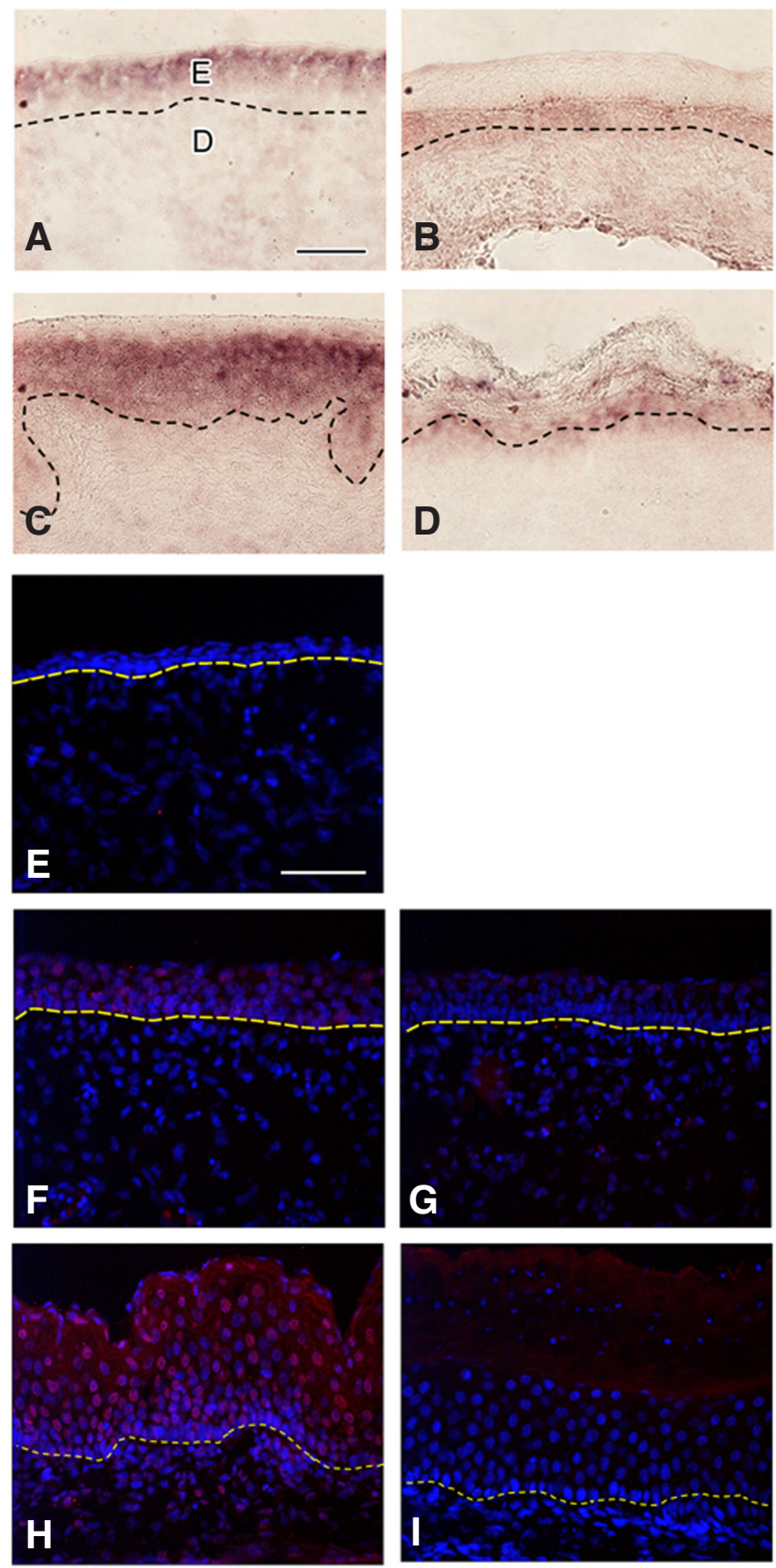

Fig. 5. Increase in expression of $\mathrm{mRNA}$ and protein of $\mathrm{Gbx} 1$ in epidermis by retinoic acid (RA). In situ hybridization analysis of Gbx1 mRNA. 16E rat embryonic skin (E) was cultured for $24 \mathrm{~h}$ in RPMl1640 containing 20 $n M$ hydrocortisone with $(\mathbf{A}, \mathbf{C}, \mathbf{F}, \mathbf{H})$ or without $(\mathbf{B}, \mathbf{D}, \mathbf{G}, \mathbf{I}) 1 \mu \mathrm{M} R A$ and then in RPMI for 4 days (C, $\mathbf{D}, \mathbf{H}, \mathbf{I})$. (E-I) DAPI nuclear counterstain. Dotted lines show boundary between epidermis and dermis. E, epidermis; $D$, dermis. Scale bars, $100 \mu \mathrm{m}$. terminal differentiation of keratinocytes accompanying in TG1, 3 or 5 (Steinert et al., 1996; Zhang et al., 2005; Candi et al., 2002) is induced by high concentration of $\mathrm{Ca}^{++}$(Reiss and Zhou 1989).

\section{Increase in epidermal Gbx1 expression by $R A$}

As described in introduction, Gbx1 might be a key regulator of epithelial differentiation. Here, we showed that, in rat embryonic skin, expression of Gbx1 mRNA was increased in the epidermis of the skin cultured for 1 day in the presence of RA (Fig. 5A) and in that cultured for additional 4 days without RA (Fig. 5C) when compared with control skin (Fig. 5 B,D). Increase in expression of Gbx1 mRNA after $8 \mathrm{~h}$ of RA treatment and 4 days later was also observed by RT-PCR analysis (Fig. 2K). Expression of Gbx1 protein was not observed in skin without culture (Fig. 5E) and was seen mainly in the nuclei of the epidermis of skin cultured for 1 day in the presence of RA (Fig. 5F) and cultured for an additional 4 days without RA (Fig. $5 \mathrm{H}$ ). Slight expression of Gbx1 protein in nuclei was seen in the dermis of RA-pretreated skin (Fig. 5 F,H) but not in control skin (Fig. 5 G,I). Hence, Gbx1 might act as a transcriptional factor and function to regenerate mucosal epithelium from the epidermis.

\section{Rounded cells in upper layers of epidermis without keratiniza- tion was appeared by overexpression of TG2/Gh and Gbx1 in the epidermis}

To elucidate the function of TG2/Gh and Gbx1 in the epidermis, we tried to transfect these genes to the epidermis by electroporation, as achieved previously (Obinata and Akimoto 2005). Luminescence of EGFP, which had been electroporated in the epidermis of the skin, was observed in the epidermis after culture for 1 day (Fig. $6 \mathrm{~A})$. So, it was confirmed that the gene transferred into the plasmid expressed the expected protein in the skin. As coding sequence of rat $G b x 1$ is not fully resolved and similarity of $G b x 1$ between mouse and rat is 96\%, we used mouse Gbx1 (mGbx1). Human $\operatorname{tg} 2 / G h$ ( $h T$ TM/Gh) was used as the gene similarity between human and rat is $94 \%$ (Genome Biology, Map element, Genome Net and sequence analysis (BLAST) were used). After both hTG2/ $G h$ and mGbx1 were electroporated into the epidermis of the skin and the skin was cultured for 5 days in RPMI1640 without $\mathrm{RA}$ and serum, epidermal keratinization and expression of $\mathrm{K} 10$, which was specifically expressed in the epidermis (Fig. 6K), were inhibited. Instead, rounded cells in the upper layer of the epidermis with removal of uppermost peridermal layer was observed (Fig. $6 \mathrm{~B}, \mathrm{~J})$, which is usually observed during differentiation, although epidermis keratinized in skin electroporated with either TG2/Gh, Gbx1, or pcDNA (Fig. 6 D,E,F) and K10 expression (Fig. 6K) were observed in pcDNA-transfected skin. On the other hand, neither PAS-stained granules (Fig. 6 C,G-I) nor MUC4 and K4 (data not shown) expression were observed in the skin overexpressing both TG2/Gh and Gbx1 genes. So, it was indicated that these 2 genes play important roles in RA-induced transdifferentiation. When the skin transfected with two genes was cultured with TGF- $\beta$, no transdifferentiation was observed (data not shown).

\section{Involvement of TGF- $\beta$ signal pathway in RA-induced epidermal transdifferentiation to mucous epithelium}

As RA increased the expression of TGF- $\beta 2$ in the dermal papilla (Foitzik et al., 2005), immunostaining with pan-TGF- $\beta 1,-\beta 2,-\beta 3$ $\mathrm{mAb}$ and experiments with inhibitors of the TGF- $\beta$ signal pathway 

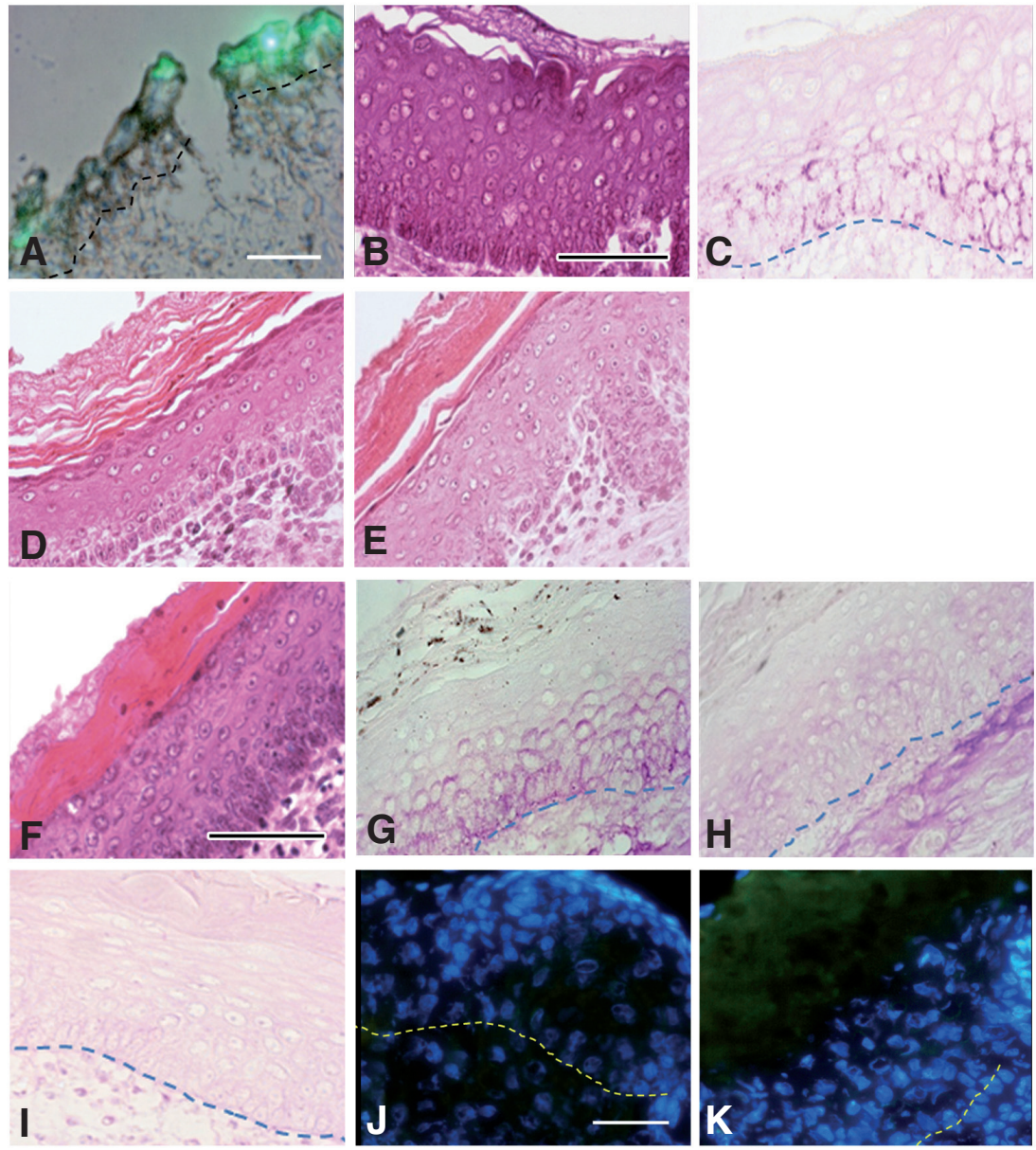

Fig. 6. Appearance of cuboidal cells on the upper layer of epidermis without keratinization by ectopic expression of both $\mathbf{h T G} 2$ and $\mathbf{m G b x} 1$ in the epidermis. 16E rat embryonic skin was transfected with pEGFP (A), hTG2 and mGbx1 (B,C,J), hTG2 (D,G), mGbx $1(\mathbf{E}, \mathbf{H})$ or pcDNA (F,I,K) by electroporation and then cultured for 1 (A) or 5 days (B$\mathbf{K})$. Fluorescent micrographs of skin sections of a single image of luminescence of EGFP (green, A). Luminescence was seen in the epidermis. (B,D-F) Hematoxylin and eosin-stained sections. Keratinized layer of the epidermis was stained red to orange. (C, G-I) Periodic acid-Schiff-stained (PAS) section. Epidermis was not stained with PAS compared to Fig. 1C $(\mathbf{J}, \mathbf{K})$ Immunostaining with anti-K10 (Green). K10 was seen in pcDNA-transfected epidermis, but was not in $h \mathrm{TG} 2$ and $m \mathrm{Gbx} 1$ transfected epidermis. (J-K) DAPI nuclear counterstain (Blue). Cuboidal cells on the upper layer of epidermis were observed with peridermal peeling by ectopic expression of both hTG2 and mGbx1 in the epidermis (B). Scale bars, $100 \mu \mathrm{m}$.

were performed to see whether TGF- $\beta$ is involved in RA-induced transdifferentiation. Immunohistological study indicated that TGF- $\beta$ was expressed in the dermis in clusters but only slightly in the epidermis in the skin cultured for 1 day with RA (Fig. $7 \mathrm{~A}$, B), while it was not in control skin (Fig. 7C). Analysis by RT-PCR confirmed increased expression of TGF- 32 after $8 \mathrm{~h}$ of RA treatment but showed almost the same expression after culture for 4 days (Fig. 2K). SB431542, a specific inhibitor of ser/thr kinase of TGF- $\beta$ type II receptor (Inman et al., 2002), and pan-TGF- $\beta 1,-\beta 2$, $-\beta 3 \mathrm{mAb}$, a neutralizing antibody, respectively partially suppressed the expression of K4 (Fig. $7 \mathrm{D}, \mathrm{J}$ ) and MUC4 (data not shown). The appearance of PAS-positive granules (Fig. $7 \mathrm{I}, \mathrm{O}$ ) in the epidermis of RA-pretreated skin were inhibited by inhibitors (Fig. 7 F,L) but epidermal morphology was unchanged (Fig. 7E,K) when compared with those of RA-pretreated skin without inhibitors (Fig. 7 G-I,M-O). As RA increased the expression of TGF- $\beta$ in the dermis, it was suggested that the interaction between the epidermis and dermis might have an important role in epidermal transdifferentiation to mucous epithelium.

Our previous study indicated that transdifferentiation of the epidermis to mucous epithelium accompanying the appearance of many mucous granules (Obinata et al., 1991b) can be induced by culturing recombinant undifferentiated epidermis or skin with retinol-pretreated dermal fibroblasts in chick embryonic tarsometatarsal skin (Obinata etal., 1987; Obinata, et al., 1994), and that the transdifferentiation activity of the dermis decreased with half life of 2 days (unpublished data), indicating that the early increase in expression of TGF- $\beta$ by RA in the dermis (Fig. $7 \mathrm{~A}, \mathrm{~B}$ ) is important for epithelial-mesenchymal interaction.

\section{RA directly transdifferentiated transient amplify-} ing cells, not stem cells, to mucosal cells

We wanted to know whether RA-induced transdifferentiation was carried out through undifferentiated stem cells or self-duplication of transient amplifying cells. Hair follicles are one of the proliferative units of the epidermis; another is the epidermal proliferative unit. Each unit has stem cells in the bulge region or interfollicular epidermis (Schreder et al., 2010) but stem cells are quiescent few in number compared with their transient amplifying cell progeny.

The transient amplifying cells in the epidermal basal and supra basal cell layers move to the intermediate layer of the epidermis, no longer proliferate, and finally reach the upper keratinized layer of the epidermis accompanying cell death. When the nuclear DNA of transient amplifying cells in the epidermis was pulse-labeled with $\mathrm{BrdU}$ for $2 \mathrm{~h}$ in the absence of RA (Fig. 8A) and then the skin was cultured for 1 day with or without RA followed by culture for 4 days, epidermal cells with labeled nuclei in the control skin moved upward, finally reached the keratinized layer and disappeared (Fig. 8C). On the other hand, the labeled transient amplifying cells in basal or suprabasal cell layers of the RA-pretreated skin moved to the intermediate and upper cell layers of the epidermis (Fig. 8B), where all the epidermal cells were transdifferentiated. If the stem cell was labeled, it did not move upward and stayed in the original position. Hence, it was indicated that labeled cells in the intermediate and upper cell layers of the epidermis transdifferentiated from the transient amplifying cells, not from undifferentiated stem cells.

\section{Discussion}

Our present study provides strong evidence that RA induced transdifferentiation of the epidermis of embryonic rat skin to the esophageal-like mucosal epithelium. As keratin filaments were not observed throughout the epidermis and both K4 and MUC4, markers of esophageal cells, were expressed in RA-induced transdifferenti- 
ated epithelial cells, not in control epidermal cells, all the cells in the epidermis without exception were induced to transdifferentiate. This transdifferentiation of whole epidermal tissue to mucosal tissue was established without any gene transfection with as short as 1-day treatment. So, this is an exciting model for induction of tissue organization, regeneration and transdifferentiation, and will provide a useful method for regeneration of skin or other tissues culture system. Thus we examined what genes are induced by RA and how they mimic epithelial-mesenchymal interaction. We focused 3 genes, TG2/Gh, Gbx1 and TGF- $\beta$, because we (Obinata et al., 2001) and others (Lichti and Yuspa, 1985a: Foitzik et al., 2005) showed these genes are induced by RA. We showed that expression of TG2/Gh protein was increased throughout the epidermis after culture for 1 day. TG2/Gh was seen in the cytoplasm, nuclei and the area of cell adhesion in the intermediate and upper layers of the epidermis reflecting multifunctional protein of TG2/ Gh (Fesus and Piacentini, 2002; Nakaoka et al., 1994; Mishra and Murphy, 2004; Tucholski and Johnson, 2003). Interestingly, in situ transamidase activity of TG2/Gh was not detected in RA-treated
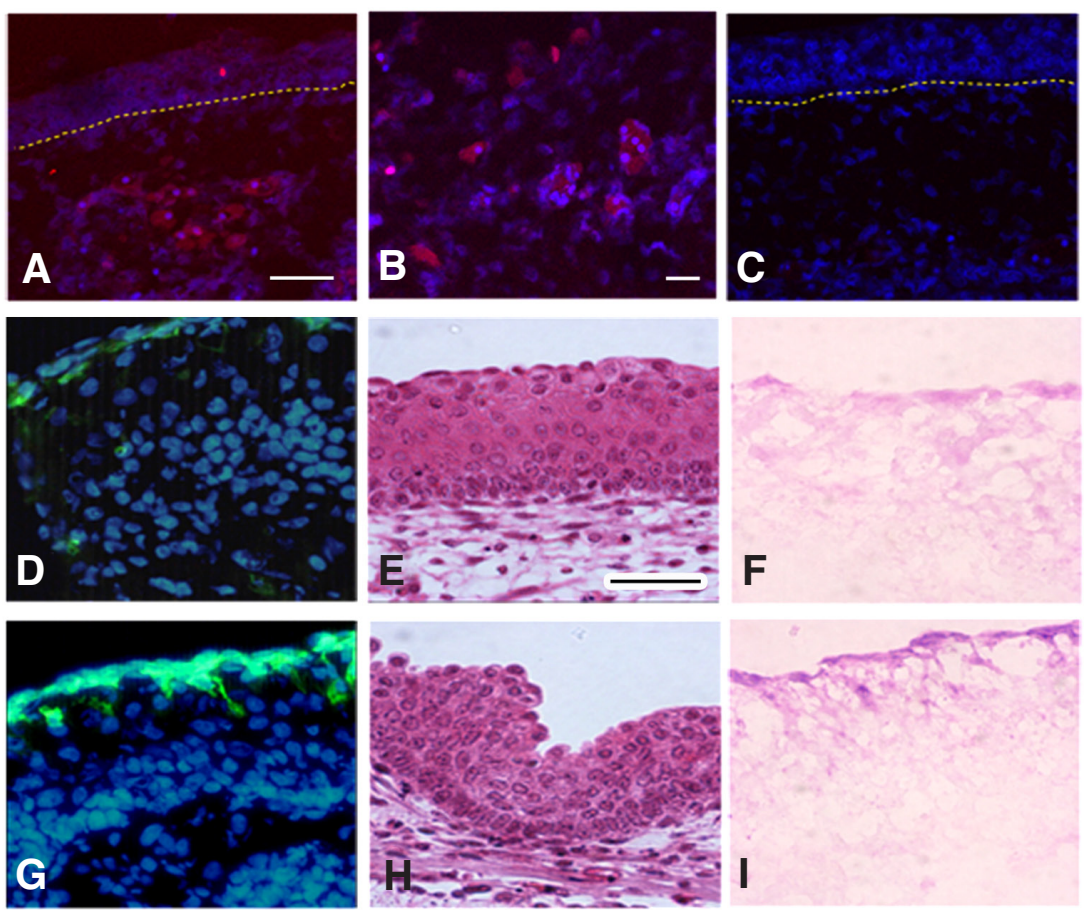

$\mathbf{F}$
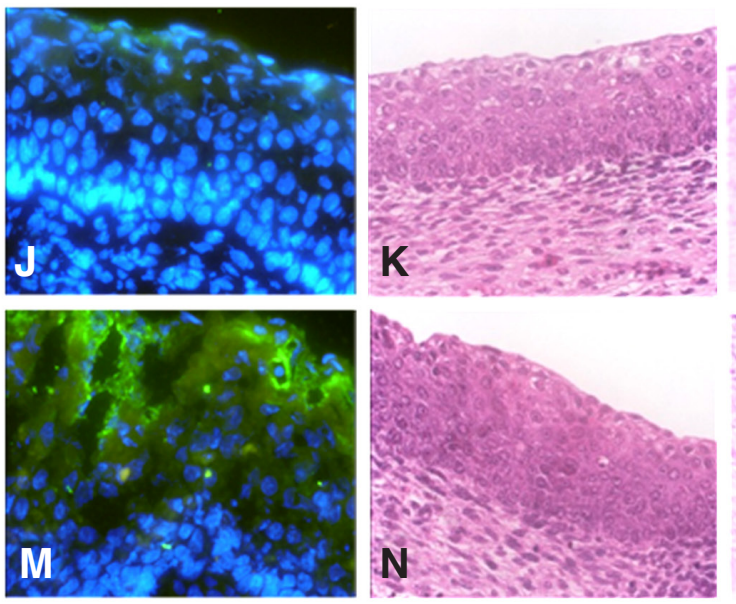

skin, suggesting that other enzyme activities of multifunctional TG2/Gh protein (Fesus and Piacentini, 2002) might be involved in transdifferentiation. In fact, RA-induced transdifferentiation was not inhibited by a transamidase inhibitor, ZM449829 (Lai et al., 2008), in the range of 100-300 nM (unpublished data).

Gbx1 is a divergent type of homeobox gene and acts as a transcription factor. Recently, we showed that Gbx1 mRNA was expressed in epithelium of intestine and skin, and liver as early as in 7-day-old chick embryo (paper in preparation), that Gbx1 mRNA expression in epidermis was induced by combined culture of undifferentiated epidermis with RA-pretreated dermis (Obinata et al., 2001), and that overexpression of Gbx1 in chick embryonic dorsal skin induced elongation of feather bud (paper in preparation). Interestingly, we found that when HeLa cells, a human uterine cervical epitheloid adenocarcinoma, had been stably transfected with cGbx1, many clones obtained were induced morphological changes of the cells with PAS-positive granules, Golgi apparatus and microvilli. So, Gbx1 has a possibility to differentiate transformed cells to normal cells (papers in preparation). Hence, Gbx1 may be a key regulator of epithelial differentiation in addition to the known role for brain development. Here, we showed immunochistochmically that expression of Gbx1 protein started to increase in nuclei of all cells of the epidermis after culture for 1 day. As expression of mRNAs of Muc4 and Gbx1 was upregulated after $8 \mathrm{~h}$ of RA-treatment, it was suggested that Gbx1 regulated expression of $M U C 4$ with unidentified factor.

Taken together, it was suggested that TG2/Gh and Gbx1 might be required in this transdifferentiation. We confirmed this in the present study; cuboidal cells instead of keratinized layers were seen in the upper layers of the epidermis without expression of epidermal marker of $\mathrm{K} 4$ by overexpression of both TG2/Gh and Gbx1 together in the epidermis, although epidermal keratinization was observed in skin by overexpression of either TG2/Gh or Gbx1.

After genes were transfected transiently to the epidermis, epidermal cells divided several times. Hence, the concentrations of both TG2/Gh and Gbx1

Fig. 7. Increase in the expression of TGF- $\beta$ protein in the dermis of retinoic acid (RA)-pretreated skin and partial suppression by inhibitors of TGF- $\boldsymbol{\beta}$ signal pathway. 16E rat embryonic skin was cultured for $24 \mathrm{~h}$ in RPMI containing 20 nM hydrocortisone with (A,B) or without (C) $1 \mu M R A$ and then in RPMI for 4 days. (A-C) Immunostaining with anti-pan-TGF $\beta(1,2,3) m A b)$ (red). (D,G,J,M) Immunostaining with anti-K4 (green). (A-D,G,J,M) DAPI nuclear counterstain (blue). (E,H,K,N) Hematoxylin and eosin-stained section. $(\mathbf{F}, \mathbf{I}, \mathbf{L}, \mathbf{O})$ PAS-stained section. Increase in the expression of pan-TGF $\beta(1,2,3) m A b$ was observed in the dermal cells of the RA-pretreated skin (A) when compared with control skin (C). Expression of K4 was suppressed partially but squamous stratified epithelium without keratinization was still preserved by $20 \mu \mathrm{M}$ SB431542 inhibitor of TGF- $\beta$ signal pathway (D-F)or $20 \mu \mathrm{g} / \mathrm{ml}$ pan-TGF- $\beta(1,2,3) m A b$ (J-L) when compared with control skin (G-I,M-O). Inhibitors of TGF- $\beta$ suppressed the appearance of PAS-positive granules (pink-purple) in the epidermis of RA-pretreated skin $(\mathbf{F}, \mathbf{L})$ when compared with epidermis without inhibitors $(\mathbf{I}, \mathbf{0})$ Scale bars: (A, C-O) 100 um; (B) $20 \mu \mathrm{m}$. 

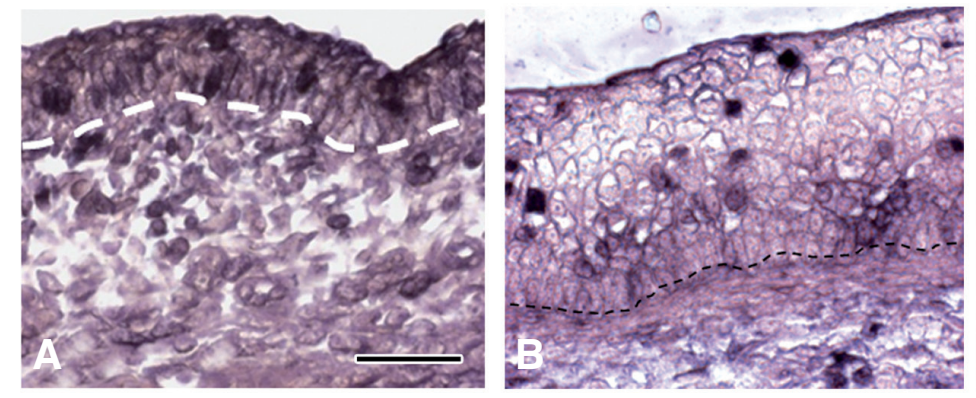

Fig. 8. Transdifferentiation of transient amplifying cells by retinoic acid (RA). Immunostaining with anti-BrdU. Nuclear DNA of the transient amplifying cells in the epidermal basal and suprabasal cell layers were labeled with BrdU for $2 \mathrm{~h}$ (A) and the skin was cultured for 1 day with (B) or without (C) RA followed by culture for 4 days (B, C). Bar, $100 \mu \mathrm{m}$.

transfected were diluted and they could not transdifferentiate the epidermis. Otherwise, some additional gene was required. We previously showed that epithelial-mesenchymal interaction was prerequisite for transdifferentiation (Obinata et al., 1994).

Here, we showed that increase in TGF- $\beta$ in the dermis by RA was involved in this interaction. A similar interesting phenomenon was observed, where RA synthesized in the mesoderm is required for dorsal endodermal expression of $P d x 1$ during the development of mouse pancreas (Molotkov et al., 2005).

As epidermal transient amplifying cells that had been labeled with BrdU in the absence of RA moved to the upper layers of the epidermis after RA treatment, it was indicated that transient amplifying cells, not stem cells, were transdifferentiated directly by RA. The thickness of the epidermis after culture for 5 days was more than 4 times than that of starting epidermis and almost all the basal and suprabasal transient amplifying cells including $2 \mathrm{~h}$-BrdU-labelled cells were extruded from the basal layer and

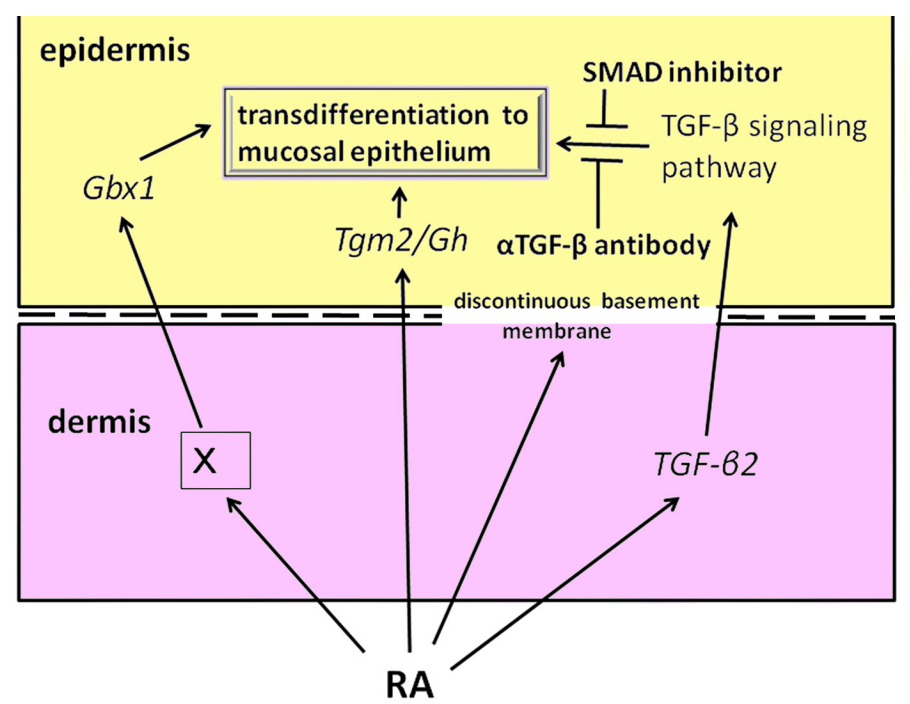

Fig. 9. Schematic diagram summarizing the effect of retinoic acid (RA) on epidermal mucosal transdifferentiation. $R A$ upregulates expression of TG2/Gh and TGF- 32 in the epidermis and the dermis respectively after 8-24 h of treatment followed by appearance of discontinuous basement membrane (Obinata et al., 1991a). On the other hand, Gbx1 expression is upregulated in the epidermis after $8 \mathrm{~h}$ by an unknown factor " $X$ ", which is induced in the dermis by RA (Obinata et al., 2001), and TGF- $\beta$ signaling pathway activated byTGF- $\beta$ together with Gbx 1 induced epidermal transdifferentiation to esophagus-like mucosal epithelium.

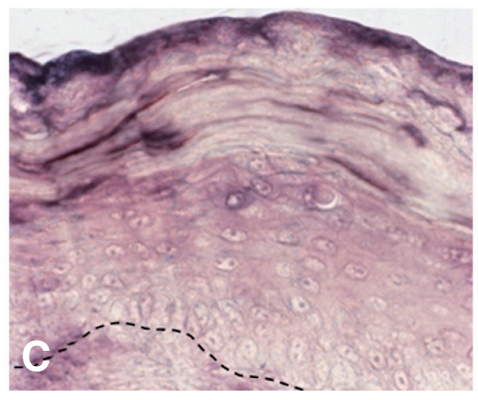

moved to intermediate and finally upper layers of epidermis during culture. Taken together, epidermal proliferation was very active and homeostasis in the epidermis was maintained via the self-renewing ability of the epidermal stem-cell population, which gives rise to differentiated cells.

Taken together, it was indicated that the transdifferentiation of epidermal cells to esophageal-like epithelial cells by RA started after 1 day without cell division through epithelial-mesenchymal interaction, and that TG2/Gh, Gbx 1 and TGF- $\beta$ were all involved in the regulation of transdifferentiation (Fig. 9).

This study provides an example of cellular reprogramming by RA in embryonic skin and suggests that RA can direct cell reprogramming to another cell without reversion to a pluripotent stem cell. It is of interest to know whether adult skins can transdifferentiate by RA treatment. Direct transdifferentiation has been shown in exocrine cells to $\beta$-cells in adult mouse pancreas by transfection of 3 transcription factors after 3 days (Zhou et al., 2008) and in $\mathrm{MEF}$ to functional neuronal cells with long, branching processes by infection of 3 transcription factors after 5 days (Vierbuchen et al., 2010). These and our studies are in contrast with a recent report of reprogramming fibroblasts to embryonic stem cells (Takahashi and Yamanaka 2006), where it takes a considerably longer time (7-30 days) with much reduced efficiency (typically less than $0.1 \%$ ). This may be due to the fact that, in the case of direct transdifferentiation, they occur in cell types that share much of their epigenomes, whereas the epigenomes of fibroblasts and embryonic stem cells are largely dissimilar. It is generally thought that epigenetic changes that underlie reprogramming events are most easily made during cell division. Hence, transdifferentiation of epidermal cells to esophageal-like mucosal epithelial cells may therefore require fewer epigenetic changes. As the generation of these transdifferentiated cells is fast, efficient and devoid of tumorigenic pluripotent stem cells, these cells can provide a novel system for regenerative medicine. Furthermore, this study showed that transdifferentiation could be induced simply by the addition of RA without transfection of genes at the tissue level.

RA is a general differentiation and transdifferentiation agent for the generation of neurons in rats (Maden and Hind 2003), lens regeneration from the iris in newts (Grogg et al., 2005), and control of cell differentiation, morphogenesis and regeneration in amphibian development and murine ES cells (Kurisaki et al., 2010); hence, we suppose that RA is a regeneration-inducing molecule (Maden and Hind 2003). By developing our system, it will become an easier, more useful and safer method for regenerative medicine with many benefits.

\section{Materials and Methods}

\section{Animals}

All animal experiments were carried out in accordance with the guidelines of the Committee of Animal Care and Experiments of Teikyo 
TABLE 1

\section{PRIMERS USED FOR RT-PCR}

\begin{tabular}{lcl}
\hline$\beta$-actin & S & GGA TGA CGA TAT CGC TGC G \\
tgm2 & AS & CAA CAC AGC CTG GAT GGC T \\
& S & TGT CTG ACG ATG TGG AGG AG \\
Gbx1 & ACT CCA CCC AGC AGT GGA AA \\
& A & AAG CTA AAG GGA AGC CTG GGG ACT \\
TGF- $\beta 2$ & AS & CAT CTG TTG GTG CTG GCT GCG CAC \\
& S & CCA AAG ACC TAA CAT CTC CAA CC \\
& AS & TGT TCG ATC TTG GGC GTA TTG C
\end{tabular}

University. The pregnant rats were anesthetized with diethyl ether and the back skins of embryos were isolated.

\section{Skin culture}

Back skin explants from 16-day-old rat embryos that had been cultured for 1 day in RPMI1640 (Sigma) containing 5\% delipidized FCS (dFCS) and $20 \mathrm{nM}$ hydrocortisone hemisuccinate (Japan Upjohn Ltd., Tokyo) with or without $1 \mu \mathrm{M}$ RA (Sigma) were cultured for 4 days in RPMI1640; the Millipore filter-roller-tube method was used for this (Sugimoto and Endo 1971). $10 \mu \mathrm{g} / \mathrm{ml}$ cycloheximide (Sigma) was used for inhibition of protein synthesis. The skin was cultured in a closed tube in the dark.

\section{Quantitative reverse transcriptase-polymerase chain reaction}

Total RNA was prepared from 16-day-old rat embryonic dorsal skin using Trizol LS reagent (Life Technologies Corporation, Carlsbad, CA, U.S.A.) according to the instruction manual. Total RNA was reversetranscribed using M-MLV reverse transcriptase (Life Technologies Corporation, Carlsbad, CA, U.S.A.) using poly $(\mathrm{dT})_{20}$ primer. Primers for quantitative RT-PCR were designed by Primer Express Software (Life Technologies Corporation). The sequences of primers were as follows: MUC4, 5'-TACTGTCACAATGGAGGCCAA -3' and 5'-AGGAGAACTTGTTCATGGAGCA -3'; $\beta$-actin, 5'-CCTAGCACCATGAAGATCAAGAT -3' and 5'-AACAGTCCGCCTAGAAGCATTT -3'. The PCR was performed with SYBR Premix EX Taq II (Takara Bio Inc., Shiga, Japan) by Applied Biosystems 7500 Real-Time PCR Systems. The results were analyzed by accessory software in real-time PCR. The amounts of MUC4 transcript was normalized by that of $\beta$-actin.

The expression of other genes was analyzed by RT-PCR. Reproducible typical results from 3 experiments with various cycles with logarithmic phase were shown. Primers are shown in Table 1.

\section{Staining for light microscopy}

Skin explants were processed for light microscopic observations (Obinata et al., 1987). Sections were stained with Mayer's hematoxylin and eosin (HE) or periodic acid-Schiff (PAS) stain.

\section{Immunostaining for light and electron microscopy}

Frozen skin sections were processed for immunohistochemical staining as described previously (Akimoto et al., 1992).

Skin was stained with 1:20 diluted anti-human cytokeratin 4 mouse monoclonal antibody (6B10; American Research Products), 1:10 diluted anti-human cytokeratin 10 mouse monoclonal antibody (RKSE60; American Research Products), 1:100 diluted anti-rat MUC4 mouse monoclonal antibody (4F12; Developmental Studies Hybridoma Bank), 1:200 diluted anti-human TG2 rabbit monoclonal antibody (D11A6; Cell Signaling), 1:200 diluted anti-human Gbx1 (N-13) goat antibody (Santa Cruz), 1:20 diluted anti- bovine TGF- $\beta 1,-\beta 2,-\beta 3$ mouse monoclonal antibody (1D11; R\&D Systems) and 1:10 diluted anti-BrdU monoclonal antibody (Roche). The sections were observed under a laser scanning microscope (LSM 510 META, Zeiss).

\section{Preparation of digoxigenin-labeled TG2/Gh and Gbx1 RNA}

Total RNA was isolated from the skin of 16-day-old rat embryos using TRIZOL LS Reagent (Life Technology). After $1 \mu \mathrm{g}$ total RNA was reverse transcribed at $37^{\circ} \mathrm{C}$ for $2 \mathrm{~h}$ with oligo $\mathrm{dT}_{20}$ and $M-M L V$ reverse transcriptase (Gibco BRL), 50 ng cDNA was used for the PCR reaction of TG2/Gh and Gbx1 with Ampli Taq Gold DNA polymerase (ABI). The oligonucleotides synthesized for RT-PCR were derived from neighboring exons and were: 5'-CCTGGAGAGGTGCGATTT -3'(TG2/Gh, sense), 5'-TCTTCACAGGGATCTGGG -3' (TG2/Gh, antisense), nucleotides 74265 in TG2/Gh gene: 5'-CCGCCTCCGCACTTCTTCA -3' (Gbx1, sense), 5'-AGGCGTGGTGACCCCTGT-3' (Gbx1, antisense), nucleotides 433-702 in the Gbx1 gene. The PCR steps included initial denaturation at $95^{\circ} \mathrm{C}$ for $12 \mathrm{~min}$ followed by denaturing at $95^{\circ} \mathrm{C}$ for $1 \mathrm{~min}$, annealing at $48^{\circ} \mathrm{C}$ (TG2/Gh) and $52^{\circ} \mathrm{C}(G b \times 1)$ for $30 \mathrm{~s}$, and extension at $72^{\circ} \mathrm{C}$ for $1 \mathrm{~min}$ for 40 cycles. The PCR products of TG2/Gh and Gbx1 were subcloned into pT7Blue T-vector (Takara Bio, Kusatsu, Shiga, Japan) and then sequenced, respectively. The subcloned TG2/Gh pT7BlueT plasmid and Gbx1 pT7BlueT plasmid were digested with $\mathrm{Kpnl}$ and EcoRI to produce antisense probes (Takara), respectively, and the linearized plasmids were transcribed with T7 RNA polymerase in transcription reactions containing Digoxigenin-11-UTP (Roche) according to the manufacturer's instructions.

To produce the sense probe, TG2/Gh pT7BlueT plasmid was digested with EcoRI and Pstl (Takara) and the obtained DNA fragment was further subcloned into pBluescriptSK(-). The TG2/Gh pBluescriptSK(-) and Gbx1 pT7BlueT plasmid were digested with Pstl and HindIII to produce sense probe, Takara), respectively, and the linearized plasmids were transcribed with T7 or T3 RNA polymerase in transcription reactions containing Digoxigenin-11-UTP.

\section{Transgene construction}

Full-length human $\operatorname{tgm} 2 / G h$ and mouse $G b x 1$ cDNA containing the entire tgm2/Gh and Gbx1 coding region, which were generously provided by $\mathrm{Dr}$ S.Kojima (Molecular Ligand Biology Research Team, Chemical Genomics Research Group, Chemical Biology Department, RIKEN Advanced Science Institute, Japan), and Dr. S. Waters (Laboratory of Cancer and Developmental Biology, NCl-Frederick, National Institute of Health, Frederick, MD, USA) were constructed with pSG5 and pcDNA3, respectively.

\section{In situ hybridization}

In situ hybridization with the DIG-labeled probes was performed as described previously (Obinata et al., 2001).

\section{In situ transamidase activity of transglutaminase}

For TG substrates, 2mM EZ-Link 5-(biotinamido) pentylamine (Pierce) was added to the culture medium during the last $2 \mathrm{~h}$ of culture (Slaughter et al., 1992). Frozen sections were cut at $7-\mu \mathrm{m}$ thickness from OCT compound-embedded dorsal skin, mounted on $2 \%$ silanized (Nisshin EM Co., Ltd.)-coated slides, and fixed in PBS containing 2\% paraformaldehyde for $10 \mathrm{~min}$. The sections were rinsed twice in PBS for 15 min each time, and were probed with streptavidin-conjugated FITC (Sigma, 0.125U/ml) and 4', 6-diamidino-2-phenyindole, dilactate (DAPI, $2 \mu \mathrm{g} / \mathrm{ml}$ ) for $2 \mathrm{~h}$ at room temperature. After washing with PBS 3 times for 5 min each time, slides were mounted with PermaFluor (Thermo) and examined with an Olympus BX51 fluorescence microscope. Biotinylated TG substrates were extracted from the cultured skin with SDS-sample buffer containing protease inhibitors ( $1 \mathrm{mM}$ phenylmethylsulfonyl fluoride, and $2 \mu \mathrm{g} / \mathrm{ml}$ each of leupeptin, antipain, chymostatin, and pepstatin) (The Protein Research Foundation) in the absence of mercaptoethanol. The extracted protein containing biotinylated TG substrates in the presence of mercaptoethanol was separated through standard SDS-10\% polyacrylamide gel electrophoresis, and then was transferred to a nitrocellulose membrane. The membrane was probed using streptavidin-conjugated horseradish peroxidase (GE Healthcare) at a dilution of 1:3000 at room temperature for $15 \mathrm{~min}$. ECL Western blotting detection reagents and analysis system (GE Healthcare) was used for detection of immobilized streptavidin-conjugated horseradish peroxidase. Protein concentration 
was determined in the absence of mercaptoethanol using a BCA Protein Assay Kit (Pierce). These experiments were performed according to the manufacturer's instructions. Equal amounts of protein $(30 \mu \mathrm{g})$ were loaded per well.

\section{In vitro transamidase activity of TG}

A microtiter plate transglutaminase assay utilizing 5-(Biotinamido) pentylamine as a substrate was performed as previously described (Lai et al., 2008). In brief, skin was homogenized by a Teflon homogenizer and sonicated for $20 \mathrm{~s}$ in $5 \mathrm{mM}$ Tris- $\mathrm{HCl}, \mathrm{pH} 7.4,0.25 \mathrm{M}$ sucrose, $0.2 \mathrm{mM} \mathrm{MgSO}_{4}$, $2 \mathrm{mM}$ dithiothreitol, $0.4 \mathrm{mM}$ phenylmethylsoufonyl fluoride, and $0.4 \%$ TritonX-100. Skin lysate (0.02mg protein) was then loaded on to Nunc-Immuno Module plates previously coated with $20 \mathrm{mg} / \mathrm{ml} \mathrm{N}, N$-dimethylcasein. The lysate was incubated for $1 \mathrm{~h}$ in $100 \mathrm{mM}$ Tris, $\mathrm{pH} 8.5,20 \mathrm{mM} \mathrm{CaCl}_{2}, 40 \mathrm{mM}$ dithiothreitol, and $2 \mathrm{mM} 5$-(biotinamido)pentylamine(BP) (Pierce), and the bound BP was detected as described (Slaughter et al., 1992).

\section{Electroporation}

Back skin of a 16E rat embryo attached to a Millipore filter $(0.45 \mu \mathrm{m}$ pore size) was placed in a small $1 \%$ agarose chamber $(10 \mathrm{H} \times 6 \mathrm{D} \times 1 \mathrm{~W}$ $\mathrm{mm}^{3}$ ) filled with PBS containing 3-3.3 $\mu \mathrm{g} / \mathrm{ml}$ plasmid with the epidermal side toward the cathode as described previously (Reiss and Zhou 1989). Electroporation was performed using an electro Square Portor T820 (BTX) generating square pulses (30V, pulse length $100 \mathrm{~ms}, 7$ times).

\section{Immunocytochemical assay for the detection of bromodeoxyuridine incorporation into cellular DNA}

The cultured skin was cut into $2 \mathrm{~mm}^{2}$ pieces and incubated in medium containing $10 \mu \mathrm{M}$ bromodeoxyuridine (BrdU) for $2 \mathrm{~h}$, fixed with Bouin solution, embedded in paraffin and cut into $5 \mu \mathrm{m}$ sections as described previously (Obinata and Akimoto 2005). After being dewaxed and rehydrated, the sections were incubated with anti-BrdU mouse monoclonal antibody (Roche) and then with alkaline phosphatase-conjugated anti mouse-lg followed (according to the manufacturer's instructions) by the substrate reaction.

\section{Acknowledgements}

We thank Dr S.Kojima for providing human tgm2 cDNA and Dr. S. Waters for providing a mouse full length Gbx1 cDNA. We are grateful to Ms. S. Matsubara and Ms. T. Miura for their technical support. This work was supported, in part, by Grants-in-Aid from the Ministry of Education, Science, Sports, Culture and Technology, Japan.

\section{References}

AKIMOTO, Y., OBINATA, A., ENDO, H. and HIRANO, H. (1992). Immunohistochemical study of basement membrane reconstitution by an epidermis-dermis recombination experiment using cultured chick embryonic skin: induction of tenascin. $J$ Histochem Cytochem 40: 1129-1137.

ANTONYAK, M.A., SINGH, U.S., LEE, D.A., BOEHM, J.E., COMBS, C., ZGOLA, M.M., PAGE, R.L and CERIONE, R.A. (2001). Effects of tissue transglutaminase on retinoic acid-induced cellular differentiation and protection against apoptosis. J Biol Chem 276: 33582-33587.

ASBREUK, C.H.J., VAN SCHAICK, H.S.A., COX, J.J., KROMKAMP, M., SMIDT, M.P. and BURBACH, J.P.H. (2002). The homeobox genes $L h x 7$ and $G b x 1$ are expressed in the basal forebrain cholinergic system. Neuroscience 109: 287-298.

BRAGULLA, H.H. and HOMBERGER, D.G. (2009). Structure and functions of keratin proteins in simple, stratified, keratinized and cornified epithelia. JAnat214:516-559.

CANDI, E., ODDI, S., PARADISI, A., TERRINONI, A., RANALLI, M., TEOFOLI, P., CITRO, G., SCARPATO, S., PUDDU, P. and MELINO, G. (2002). Expression of transglutaminase 5 in normal and pathologic human epidermis. J Invest Dermatol 119: 670-677.

DALBY, K.N., TAKEDERELI, I., LOPEZ-BERESTEIN, G. and OZPOLAT, B. (2010). Targeting the prodeath and prosurvival functions of autophagy as novel therapeutic strategies in cancer. Autophagy 6: 322-329.

FESUS, L. and PIACENTINI, M. (2002). Transglutaminase 2: an enigmatic enzyme with diverse functions. Trends Biochem Sci 27: 534-539.

FOITZIK, K., SPEXARD, T., NAKAMURA, M., HALSNER, U. and PAUS, R. (2005) Towards dissecting the pathogenesis of retinoid-induced hair loss: all-trans retinoic acid induces prematurer hair follicle regression (catagen) by upregulation of transforming growth factor- $\beta 2$ in the dermal papilla. J Invest Dermatol 124: 1119-1126.

GROGG, M.W., CALL, M.K., OKAMOTO, M., NATALIA VERGARA, M., DEL RIOTSONIS, K. and TSONIS, P.A. (2005). BMP inhibition-driven regulation of six-3 underlies induction of newt lens regeneration. Nature 438: 858-862

GUILLEM, P., BILLERET, V., BUISINE, M.-P., FLEJOU, J.-F., LECOMTE-HOUCKE, M., DEGAND, P., AUBERT, J.-P., TRIBOULET, J.-P., and PORCHET, N. (2000). Mucin gene expression and cell differentiation in human normal, premalignant and malignant esophagus. Int J Cancer 88: 856-861.

INMAN, G.J., NICOLÁS, F.J., CALLAHAN, J.F., HARLING, J.D., GASTER, L.M., REITH, A.D., LAPING, N.J., and HILL, C.S. (2002). SB-431542 is a potent and specific inhibitor of transforming growth factor- $\beta$ superfamily type lactivin receptorlike kinase (ALK) receptors ALK4, ALK5, and ALK7. Mol Pharmacol 62: 65-74.

KURISAKI, A., ITO, Y., ONUMA, Y., INTOH, A. and ASASHIMA, M. (2010). In vitro organogenesis using multipotent cells. Hum Cell 23: 1-14.

LAI, T.S., LIU, Y., TUCKER, T., DANIEL, K.R., SANE, D.C., TOONE, E., BURKE, J.R., STRITTMATTER, W.J. and GREENBERG, C.S. (2008). Identification of chemical inhibitors to human tissue transglutaminase by screening existing drug libraries. Chem Biol 15: 969-978.

LICHTI, U. and YUSPA, S.H. (1985a). Inhibition of epidermal terminal differentiation and tumour promotion by retinoids. Ciba Found Symp 113: 77-89.

LICHTI, U., BEN, T. and YUSPA, S.H. (1985b). Retinoic acid-induced transglutaminase in mouse epidermal cells is distinct from epidermal transglutaminase. $J$ Biol Chem 260: 1422-1426.

LORAND, L. and GRAHAM, R.M. (2003). Transglutaminases crosslinking enzymes with pleiotropic functions. Nature 4: 140-156.

MADEN, M. and HIND M. (2003). Retinoic acid, a regeneration-inducing molecule. Dev Dyn 226: 237-244.

MISHRA, S. and MURPHY, L.J. (2004). Tissue transglutaminase has intrinsic kinase activity: identification of transglutaminase 2 as an insulin-like growth factor-binding protein-3 kinase. J Biol Chem 279: 23863-23868.

MOLOTKOV, A., MOLOTKOVA, N. and DUESTER, G. (2005). Retinoic acid generated by Raldh2 in mesoderm is required for mouse dorsal endodermal pancreas development. Dev Dyn 232: 950-957.

NAKAOKA, H., PEREZ, D.M., BAEK, K.J., DAS, T., HUSAIN, A., MISONO, K., IM, M.-J. and GRAHAM, R.M. (1994). G: A GTP-binding protein with transglutaminase activity and receptor signaling function. Science 264: 1593-1596.

NANDA, N., IISMAA, S.E., OWENS, W.A., HUSAIN, A., MACKAY, F. and GRAHAM, R.M. (2001). Targeted inactivation of $\mathrm{G}_{\mathrm{h}} /$ tissue transglutaminase II. J Biol Chem 276: 20673-20678

NESS, S.L., EDELMANN, W., JENKINS, T.D., LIEDTKE, W., RUSTGI, A.K. and KUCHERLAPATI, R. (1998). Mouse keratin 4 is necessary for internal epithelial integrity. J Biol Chem 273: 23904-23911.

OBINATA, A., KAWADA, M. and Endo, H. (1987). Induction of epidermal mucous metaplasia by culture of recombinants of undifferentiated epidermis and retinoltreated dermis in a chemically defined medium. Dev Biol 123: 59-62.

OBINATA, A., AKIMOTO, Y., HIRANO, H. and ENDO, H. (1991a). Short term retinol treatment in vitro induces stable transdifferentiation of chick epidermal cells into mucus-secreting cells. Roux's Arch Dev Biol 200: 289-295.

OBINATA, A., AKIMOTO, Y., HIRANO, H. and ENDO, H. (1991b). Stimulation by $\mathrm{Bt}_{2} \mathrm{CAMP}$ of epidermal mucous metaplasia in retinol-pretreated chick embryonic cultured skin, and its inhibition by herbimycin A, an inhibitor for protein-tyrosine kinase. Exp Cell Res 193: 36-44.

OBINATA, A., AKIMOTO, Y., KAWAMATA, T. and HIRANO, H. (1994). Induction of mucous metaplasia in chick embryonic skin by retinol-pretreated embryonic chick or quail dermal fibroblasts through cell-cell interaction: Correlation of a transient increase in retinoic acid receptor $\beta$ mRNA in retinol-treated dermal fibroblasts with their competence to induce epidermal mucous metaplasia. Develop Growth Differ 36: 579-587.

OBINATA, A., AKIMOTO, Y., OMOTO, Y. and HIRANO, H. (2001). Increase in expression of the homeobox gene, Gbx1, in retinol-induced epidermal mucous metaplasia. Biochem Biophys Res Commun 280: 1055-1061.

OBINATA, A. and AKIMOTO, Y. (2005). Involvement of Hex in the initiation of feather 
morphogenesis. Int J Dev Biol 49: 953-960.

OU, H., HAENDELER, J., AEBLY, M.R., KELLY, L.A., CHOLEWA, B.C., KOIKE, J., KWITEK-BLACK, A., JACOB, H.J., BERK, B.C. and MIANO, J.M. (2000). Retinoic acid-induced tissue transglutaminase and apoptosis in vascular smooth muscle cells. Circ Res 87: 881-887.

REISS, M. and ZHOU, Z.L. (1989). Uncoupling of the calcium-induced terminal differentiation and the activation of membrane-associated transglutaminase in murine keratinocytes by type-beta transforming growth factor. Exp Cell Res 183: 101-111.

RHINN, M., LUN, K., WERNER, M., SIMEONE, A. and BRAND, M. (2004). Isolation and expression of the homeobox gene Gbx1 during mouse development. Dev Dyn 229: 334-339.

SENGEL, P. (Ed) (1976). Morphogenesis of Skin. Cambridge University Press, Cambridge.

SChreder, A., PIERARd, G.E., PAQUet, P., REginster, M.A., PIERARDFRANCHIMONT, C. and QUATRESOOZ, P. (2010). Facing towards epidermal stem cells (Review). Int J Mol Med 26: 171-174.

SINGH, U.S., PANS, J., KAO, Y.-L., JOSHI, S., YOUNG, K.L. and BAKER, K.M. (2003). Tissue transglutaminase mediates activation of RhoA and MAP kinase pathways during retinoic acid-induced differentiation of SH-SY5Y cells. J Biol Chem 278: 391-399.

SLAUGHTER, T.F., ACHYUTHAN, K.E., LAI, T.S. and GREENBERG, C.S. (1992). A microtiter plate transglutaminase assay utilizing 5-(biotinamido) pentylamine as substrate. Anal Biochem 205: 166-171.
STEINERT, P.M., KIM, S.Y., CHUNG, S.I. and MARECOV, L.N. (1996). The transglutaminase 1 enzyme is variably acylated by myristate during differentiation in epidermal keratinocytes. J Biol Chem 271: 26242-26250

SUGIMOTO, M. and ENDO, H. (1971). Accelerating effect of hydrocortisone on the keratinization of chick embryonic skin growing in a chemically defined medium. J Embryol Exp Morphol 25: 365-376.

TAKAHASHI, K. and YAMANAKA, S. (2006). Induction of pluripotent stem cells from mouse embryonic and adult fibroblasts cultures by defined factors. Cell 126: 663-676.

TELCI, D. and GRIFFIN, M. (2006). Tissue transglutaminase (TG2)-a wound response enzyme. Front Biosci 11: 867-882.

TUCHOLSKI, J. and JOHNSON, G.V.W. (2003). Tissue transglutaminase directly regulates adenylyl cyclase resulting in enhanced cAMP-response element-binding protein (CREB) activation. J Biol Chem 278: 26838-26843.

VIERBUCHEN, T., OSTERMEIER, A., PANG, Z.P., KOKUBU, Y., SÜDHOF, T.C. and WERNIG, M. (2010). Direct conversion of fibroblasts to functional neurons by defined factors. Nature 463: 1035-1041.

ZHANG, J., ZHI, H.Y., DING, F., LUO, A.P. and LIU, Z.H. (2005). Transglutaminase3 expression in C57BL/6J mouse embryo epidermis and the correlation with its differentiation. Cell Res 15: 105-110.

ZHOU, Q., BROWN, J., KANAREK, A., RAJAGOPAL, J. and MELTON, D.A. (2008). In vivo reprogramming of adult pancreatic exocrine cells to $\beta$-cells. Nature 455 627-633. 


\section{Further Related Reading, published previously in the Int. J. Dev. Biol.}

Contribution of mesoderm to the developing dental papilla

Michaela Rothová, Jifan Feng, Paul T. Sharpe, Renata Peterková and Abigail S. Tucker

Int. J. Dev. Biol. (2011) 55: 59-64

Skin, cornea and stem cells - an interview with Danielle Dhouailly

Cheng-Ming Chuong

Int. J. Dev. Biol. (2009) 53: 775-782

Epithelial-Mesenchymal Transitions in development and disease: old views and new perspectives

M. Angela Nieto

Int. J. Dev. Biol. (2009) 53: 1541-1547

Comparative study of mouse and human feeder cells for human embryonic stem cells Livia Eiselleova, Iveta Peterkova, Jakub Neradil, Iva Slaninova, Ales Hamp and Petr Dvorak Int. J. Dev. Biol. (2008) 52: 353-363

TGFbeta and TGFalpha, antagonistic effect in vitro on extracellular matrix accumulation by chick skin fibroblasts at two distinct embryonic stages.

P Locci, T Baroni, C Lilli, D Martinese, L Marinucci, S Bellocchio, M Calvitti and E Becchetti Int. J. Dev. Biol. (1999) 43: 157-165

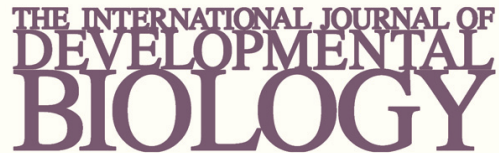

Volume 54 Nos. $6 / 7$

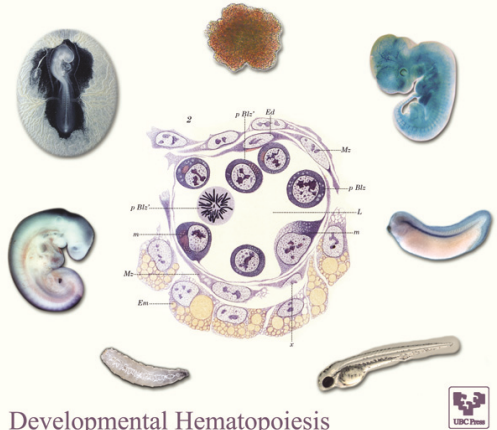

5 yr ISI Impact Factor $(2010)=2.961$

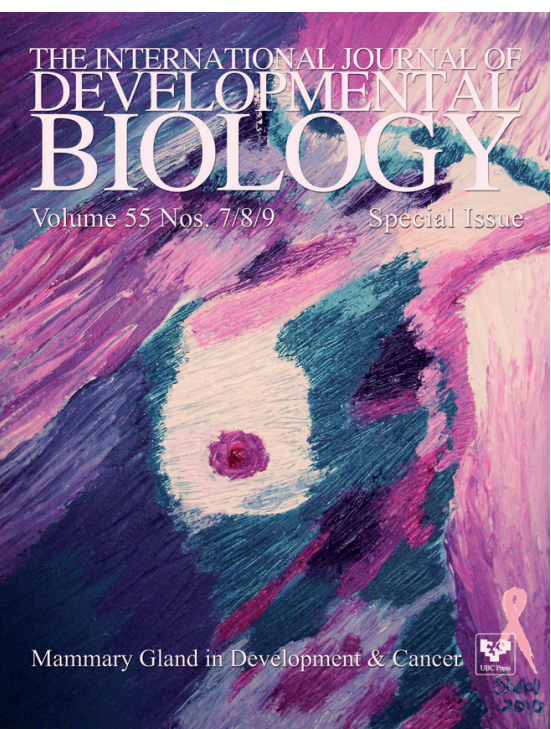

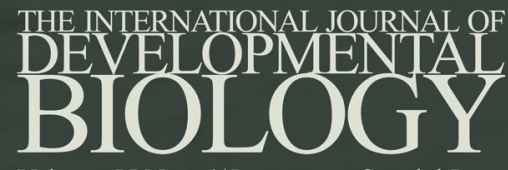

Volume 55 Nos. $4 / 5$

Special Issue

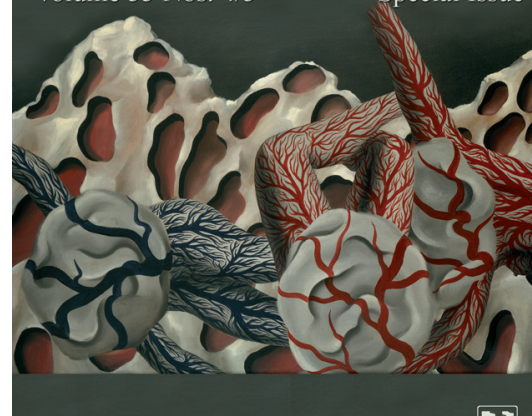

Angiogenesis in Development \& Cancer 